\title{
Eternidad y belleza. Tránsitos entre Schopenhauer y Borges
}

Javier Acosta Escareño Universidad Autónoma de Zacatecas

Resumen

Este artículo revisa algunos aspectos del binomio belleza-eternidad en la poética de Jorge Luis Borges, a partir de su relación con la filosofía del arte en Arthur Schopenhauer. Se analiza así la relación entre poesía y saber desarrollada por el filósofo pesimista y recogida por Borges.

Palabras clave: Borges, Schopenhauer, Platón, belleza, eternidad, poesía.

\section{Abstract}

This article reviews some aspects of the binomial beauty-eternity in the poetics of Jorge Luis Borges, from the point of view of his relationship with the Schopenhauer's philosophy of art. This article discusses the relationship between poetry and knowledge postulated by the pessimistic philosopher and collected by Borges.

Keywords: Borges, Schopenhauer, Plato, beauty, eternity, poetry. 


\section{Sabiduría, poesía y principio de razón}

Tifra (1981): "Mi suerte es lo que suele denominarse poesía intelectual. La palabra es casi un oxímoron; el intelecto (la vigilia) piensa por medio de abstracciones, la poesía (el sueño), por medio de imágenes, de mitos o de fábulas. La poesía intelectual debe entretejer gratamente esos dos procesos" (Borges, 1998: 571). Borges reconoce la oposición habitual entre intelecto y poesía. El intelecto es, según sus propias palabras, pensamiento en vigilia; la poesía es pensamiento ensoñante. La poesía intelectual entreteje el proceso del sueño con el proceso intelectual, la imagen con la abstracción, de ahí el oxímoron — tropo que resulta de la relación sintáctica de los opuestos, que de esa manera los hace concordar (Beristáin, 1997: 374). Encontramos en la lectura de Borges que imagen e idea son ambas formas del pensamiento: la abstracción piensa, el sueño piensa, la poesía piensa. El problema de la poesía intelectual es que nos lleva a aceptar a la imagen y al sueño como formas de la inteligencia; todavía más, la poesía intelectual supera la antítesis, aunque no dialécticamente, es decir, no filosóficamente, sino en la misma poesía, gracias a un tropo: el oxímoron.

El debate sobre sabiduría y poesía es antiguo. Baste recordar que el inicio de la contienda da también origen a la filosofía propiamente dicha, que nace ya en oposición a la sabiduría poética, tal como se recoge en los Diálogos, de Platón. Aunque tampoco ahí, en su inicio, el deslinde entre filosofía y poesía es sencillo. En el Fedro la poesía es una forma de divina locura — uno de los mayores bienes de los hombres_-, mientras que en La República, el poeta es un agente pernicioso para la polis. Borges es un conocedor insigne de la litis. En su calidad de poeta, nos enseńa que la poesía piensa y que tiene su verdad; desliza además la idea de que la filosofía 
puede ser una disimulada modalidad de la ficción; la filosofía, esa vertiente del pensamiento, no es sino una indigente rama de la literatura fantástica.

El establecimiento de este oxímoron entre poesía e intelecto tiene uno de sus precursores privilegiados en Arthur Schopenhauer, a quien Borges estudió desde temprana edad, en sus años de adolescente en Ginebra. La consideración que Borges tiene del filósofo pesimista es alta y es constante. Si la filosofía es una rama de la literatura fantástica, esta condición tiene algunas excepciones, cuando menos respecto del pensamiento de Schopenhauer, así lo declara en El Hacedor (1960): "Pocas cosas me han ocurrido y muchas he leído. Mejor dicho: pocas cosas me han ocurrido más dignas de memoria que el pensamiento de Schopenhauer o la música verbal de Inglaterra" (Borges, 1998: 170).

El pensamiento de Schopenhauer, está contenido en su temprana obra central El mundo como voluntad y representación (1819); el resto de sus libros son explicaciones y desarrollos de una extraordinaria coherencia. Como el mismo Borges señala en el poema "El pasado" recogido en El oro de los tigres (1970), Schopenhauer encuentra con precocidad la clave de su filosofía: "el joven Schopenhauer, que descubre/ el plano general del universo" (Borges, 1998: 371). Las claves del pesimismo son unas cuantas, desarrolladas con riqueza de ejemplos, especialmente literarios y artísticos, en los que se describe este plano general del universo, que al mismo tiempo es doble y es único. Mundo que es voluntad (Wille) y representación (Vorstellung). La representación está sujeta al tiempo, no así la voluntad. La voluntad, impulso ciego que habita cada cosa, es el régimen mismo de la eternidad: la voluntad puede observarse en lo temporal, pues lo constituye, pero la voluntad misma es independiente del tiempo.

El estudio de la representación schopenhaueriana nos lleva a considerar el espacio (Raum) y el tiempo (Zeit), componentes ya 
de lo que Kant llama estética trascendental en su Crítica de la razón pura (1778): entendiendo por tal estética trascendental la forma general bajo la cual nuestros sentidos perciben el mundo, binomio que conforma la "naturaleza básica" del "conocimiento sensible" (Kant, 1998: \$8, 82). Para Schopenhauer, el tiempo y el espacio, junto con la causalidad (Kausalität), componen el principio de razón. La representación nos dice qué es el mundo cuando es para un sujeto, ello la determina radicalmente. El tiempo, el espacio y la causalidad son entonces aspectos (y por tanto son) subjetivos. Como la conciencia misma, los aspectos del mundo no existen afuera del cerebro. Dicho apresuradamente: el tiempo no existe en sí mismo, es una mera consideración. Observar el mundo más allá del tiempo es para Schopenhauer la verdadera potencia del conocer, pues sólo se conoce lo que el mundo realmente es -más allá de la apariencia- cuando la conciencia puede levantarse por encima del tiempo. Así, el tiempo es un elemento de la razón representativa, la sucesión. "Este mundo como representación sólo existe para el entendimiento, al igual que sólo existe por el entendimiento" (Schopenhauer, 2003 A: $\$ 4,94$ ).

La voluntad es aquello que existe independiente de la subjetividad, constituyendo la representación desde el afuera de la representación. La voluntad es la cosa en sí del mundo: el impulso ciego que habita el corazón de cada cosa (ímpetu vital, le gusta citar a Borges) y al cual tenemos acceso sin ningún intermediario, pues la voluntad es el nombre que recibe la unidad de las apetencias, ya sean nutritivas, sexuales, mundanas, ya se trate del anhelo de preponderar sobre otros individuos y especies; pero también cuando se trata del ímpetu trascendente —el deseo de permanencia, más allá de la muerte, del individuo. Se incluye así el apetito de eternidad que se encuentra tan patentemente inscrito en la especie humana - vista la especie como correlato carnal y múltiple, o mejor dicho, numérico, de la idea de hombre-; así, la apetencia es de 
eternidad, pero también es la eternidad es fruto del deseo: "el estilo del deseo es la eternidad" escribe Borges al final del apartado III de su Historia de la eternidad — de alguna manera, podríamos intuir que el estilo del deseo está en infinitivo y carece de persona, como la voluntad de Schopenhauer.

La voluntad de Schopenhauer, como el deseo al que alude Borges, no tienen sujeto; pero todo es sujeto de la voluntad, la voluntad no está contenida por el tiempo, pero todo el tiempo está contenido en la representación.

\section{Schopenhauer y la idea platónica}

Para Platón la experiencia de la verdad es una especie de anamnesia. El alma, que ya lo ha visto todo, pues es inmortal y eterna, recuerda desde el olvidadizo ámbito de la carne, la esencia eterna de las cosas, las ideas o arquetipos. De esta guisa, la tarea del filósofo es la de recordar, por medio de una disciplina anamnética, aquello que las cosas son en esencia. Frente a las ideas, las cosas de este mundo son meras copias, carentes del verdadero ser, de ahí que las criaturas sujetas al tiempo aparezcan y desaparezcan incesantemente, sin llegar propiamente a ser. Arthur Schopenhauer resume así, al comienzo del libro tercero de El mundo como voluntad y representación, la significación de las ideas platónicas: "lo único que puede ser llamado verdaderamente ser, porque siempre es, pero nunca deviene ni desaparece, son los originales reales de esas siluetas, que son las ideas eternas, las formas primitivas (Urformen) de las cosas" (Schopenhauer, 2003 A: \$31, 261). Recuperando a Platón, Schopenhauer practica una operación de trascendente importancia, que sin embargo lo aleja del platonismo: el asunto de la esencia de las cosas no compete más a la filosofía, sino que se trata de una experiencia artística, la contemplación (Kontemplation), que consiste en observar a los objetos fuera del principio de razón. Apertura de 
la visión, del pensamiento más allá del concepto, el arte nos eleva respecto de las determinaciones del intelecto racional; en el arte se ve lo que está ahí más allá del principio de razón: la cifra eterna de las criaturas sujetas al devenir y a la ingente pluralidad. La contemplación es la operación por medio del cual el artista "suspende el tiempo", "detiene el mundo", aislando un objeto o una situación de sus referentes cronológicos (aún cuando dichos referentes se encuentren en la obra) (Schopenhauer, 2003 A: \$41, 301). Más allá de la determinación diacrónica, las visiones del arte nos emplazarían sincrónicamente con sus representaciones. Abolición del tiempo que nos permitiría ver que Hamlet o Edipo contienen la idea - y con ella, la esencia más real- del hombre.

$\mathrm{El}$ arte nos deja ver así la primitiva (y constante) forma de lo humano. La forma primitiva - el arquetipo- no es sin embargo ubicable al inicio del tiempo, sino, con toda propiedad, fuera del tiempo, mostrando el origen atemporal de lo que sucede en el tiempo. Fuera del tiempo, puesto que en el arte se contemplan más allá de la ilusión diacrónica. Así, la visión de esa atemporalidad que radica en cada cosa es la belleza; regresando a la fórmula schopenhaueriana, tenemos que la eternidad es el objeto del arte y que la belleza es la visión de la eternidad ( Vid. Schopenhauer, 2003 A: $\$ 41,301)$.

\section{El presente como arquetipo del tiempo}

El tema del tiempo y la eternidad es una de las ocupaciones constantes en la obra de Borges. Sus pormenores son abundantes y complejos, y han sido abordados en repetidas ocasiones; sin embargo, podemos defender que existe un nexo constante con las ideas de Schopenhauer, sobre todo si recuperamos la doctrina de una cierta eternidad intramundana y, para incurrir en otro oxímoron, mortal. Esa idea de eternidad permite a Borges pasar de la 
inmóvil eternidad de Platón (y Plotino) descrita en Historia de la eternidad, a la idea de una eternidad vislumbrada en la fugacidad del mundo: la verde eternidad que sostiene la apuesta de "Arte poética” poema contenido en el Hacedor (Borges, 1998; 161):

Cuentan que Ulises, harto de prodigios,

lloró de amor al divisar su Itaca

verde y humilde. El arte es esa Itaca

de verde eternidad, no de prodigios.

Tenemos entonces la eternidad desdoblada por el deseo. Eternidad metafísica (propia del concepto y la teología) y la eternidad temporal (afín a la contemplación estética), producto de ese instante poético en que la detención y el movimiento se confunden. El signo de la eternidad es transmutado así en poesía, gracias al oxímoron, a esa forma de pensamiento ensońante que Borges consideraba como la clave de toda la poesía y aquello que marca su distinción del pensamiento lógico, del conocimiento puro frente a la sabiduría mixta. "En álgebra, el signo más y el signo menos se excluyen; en literatura, los contrarios se hermanan e imponen a la conciencia una sensación mixta; pero no menos verdadera que las demás” (Borges, 1986 A: 94). Podríamos decir que para Borges hay dos tipos de eternidad, la eternidad del pensamiento diurno, a la que llamaremos, con la ayuda Schopenhauer, eternidad exotérica (sujeta al concepto) y la eternidad de la poesía-sueńo, a la que llamaremos eternidad esotérica (sujeta al oxímoron). La eternidad exotérica sería aquella que para el argentino es "una de las más hermosas invenciones del hombre" (Borges, 1980: 113). Borges la resume como la cifra total de los tres tiempos: "La eternidad es la suma de todos nuestros ayeres, todo los ayeres de todos los seres conscientes. Todo el pasado, ese pasado que no se sabe cuándo empezó. Y luego, todo el presente. Este momento presente que abarca todas las ciudades, todos los mundos, el espacio entre los planetas. 
Y luego, el porvenir. El porvenir, que no ha sido creado aún, pero que también existe" (Borges, 1980: 114). Podríamos suponer que esta visión de la eternidad es numérica, pertenece al principio de razón, es decir a la trabazón causal del tiempo. Borges advierte que se trata de los ayeres de todos los seres conscientes, puesto que asume, como Schopenhauer, que el tiempo es un fenómeno de la conciencia. Hay sin embargo en Borges esa otra eternidad, la esotérica, que aparece en los fenómenos nocturnos del sueńo y la poesía. Se trata en la esotérica, de una eternidad intramundana. Un lugar de este mundo donde no pasa el tiempo, y que comparece en ese tipo de pensamiento onírico y poético.

La idea de eternidad ultramundana, donde no pasa el tiempo, es para Borges un intento más de refutar el tiempo. También el tiempo - entendido como cronología, como medida artificial del devenir - es ya una forma de refutar el tiempo y su arquetipo. De ese modo lo señala en el poema "El otro, el mismo" (Borges, 1998: 224):

El presente está sólo. La memoria erige el tiempo. Sucesión y engaño es la rutina del reloj. El año no es menos vano que la vana historia.

Entre el alba y la noche hay un abismo de agonías, de luces, de cuidados; el rostro que se mira en los gastados espejos de la noche no es el mismo. El hoy fugaz es tenue y es eterno; otro Cielo no esperes, ni otro Infierno.

El arquetipo del tiempo es el presente; un presente incesante en el que todas las cosas se renuevan. La cifra de la eternidad esotérica es el instante: el grado eterno del presente. Frente al infinito del tiempo, la cifra del espacio es el laberinto: otro trasunto de la repre- 
sentación en irrepresentable conjunto. El laberinto es la eternidad del espacio, si algo así puede ser dicho. Por ello el tiempo se revela como un laberinto de fracciones en las que se pierde la noción normal de su paso y por la que confluyen los decursos de la más larga y la más corta duración. También por ello el laberinto es la metáfora que condensa la visión del mundo-representación en Borges.

El laberinto es la imagen que designa el abismal problema del curso temporal y el elemento designado por ausencia en la metáfora del laberinto espacial: el tiempo. El símbolo del laberinto designa esa confusión progresiva entre el universo y uno de sus detalles —uno de sus alephs_, el universo resulta así una monstruosa acumulación de fragmentos que contienen al todo. Así, junto al relato de "El Aleph", hay en "El jardín de los senderos que se bifurcan" la novela infinita de Ts'ui Pên, en la que hay otro aleph que proliferaría hasta engullir el mundo. "Pensé en un laberinto de laberintos, en un sinuoso laberinto creciente que abarcara el pasado y el porvenir y que implicara de algún modo los astros" (Borges, 1995: 107). El laberinto del tiempo cósmico se desdobla infinitamente en el laberinto del microcosmos humano, laberinto de tiempo eterno donde un hombre inmortal muere a cada instante.

\section{La verde eternidad}

Hay una eternidad, como la postulada por Plotino "que no tolera la repetición y el pleonasmo. Es el inmóvil y terrible museo de los arquetipos platónicos" (Borges, 1999: 19). Los arquetipos son causas de las causas, es decir, las ideas: "causas primordiales o ideas, que pueblan y componen la eternidad" (Borges, 1999: 19). La eternidad de Borges no es una inmóvil estación de los ejemplos del ser. El arquetipo no significa para él la eternidad atemporal del tigre, sino su juventud inmortal —su lozania y frescura-, tal y como quería Schopenhauer en su doctrina de la indestructibili- 
dad. Por medio de ella, el filósofo intenta hacer comprender a sus lectores, que la esencia misma de la vida y del mundo es eterna. Así Schopenhauer nos dirá que nuestra esencia es el principio mismo de la vida, y dicho principio es eterno, inmune a la devastación de nuestros caracteres individuales; dicho principio se encuentra de manera completa, al mismo tiempo, en la especie y en el individuo: "Pues la comprensión del carácter indestructible (Unzerstörbarkeit) de nuestro ser coincide con la de la identidad del macrocosmos y el microcosmos" (Schopenhauer, 2003 B: 539). Inmortalidad de la vida, finitud del individuo. El estatuto ontológico de los seres queda entonces, como en Schopenhauer, rarificado. No se expresa algo diferente el poema "Amanecer", reunido en Fervor de Buenos Aires: "Y ya que las ideas / no son eternas como el mármol / sino inmortales como un bosque o un río" (Borges 1998: 395). Se trata de la eternidad temporal.

Para Schopenhauer, la visión de la eternidad es la misma de la belleza; para Borges, en cada cosa en que es revelada la eternidad sobreviene la poesía. La contemplación de la "verde eternidad" es la experiencia de la belleza. La belleza es producto de la revelación en el tiempo, de lo atemporal: las cosas y las situaciones que revelan la eternidad intramundana. Así, Borges piensa que la belleza es una ocasión, y que la poesía, como la belleza, es un pasaje. Una ocasión, kairós. La idea de belleza es para Borges similar a la verdad griega; o mejor dicho, a la verdad platónica. La verdad griega es la aletheia, entendida como privación del olvido, según la mitología expuesta en el Fedro y en La república. La verdad y la belleza son ambas formas del desolvido. La poesía es una forma de desolvidar la belleza. $\mathrm{O}$ al revés, la belleza es una forma de desolvidar la poesía, ese otro pensar. Pero en principio, la poesía es una forma de desolvidar la eternidad, como afirma en el poema "La dicha" (Borges, 1998: 594): 
El que abraza a una mujer es Adán. La mujer es Eva.

Todo sucede por primera vez.

[...]

El que duerme es todos los hombres.

En el desierto vi la joven Esfinge, que acaban de labrar.

Nada hay antiguo bajo el sol.

Todo sucede por primera vez, pero de un modo eterno.

El que lee mis palabras está inventándolas.

En el poema, el lenguaje subvierte su condición temporal, su naturaleza diacrónica. Gracias al pensar poético lo que está en el tiempo (la conciencia, sujeta al principio de razón) se remonta al principio del tiempo. Arquetipo del tiempo que ahora es el instante, ocasión en que se contempla esa primera vez, en la que está sucediendo todo; he aquí entonces la gran coincidencia entre Schopenhauer y Borges, que reúnen, bajo el signo de la contemplación de la belleza, la visión de la eternidad; ocasión de un saber más allá del concepto.

\section{Bibliografía}

Borges, Jorge Luis, 1998, Obra poética, Emecé, Buenos Aires, 700 pp.

__, 1986 a, "La metáfora”, en Cosmópolis, noviembre de 1921; citado en Pellicer, Rosa, Borges: El estilo de la eternidad, Zaragoza, Pórtico, 287 pp.

— 1986 b, Borges oral, Emecé, Buenos Aires, 108 pp.

__, "El jardín de los senderos que se bifurcan", en Ficciones, 1995, Alianza, Madrid, 218 pp.

—, Historia de la eternidad, 1999, Alianza, Madrid, 177 pp.

Beristáin, Helena, Diccionario de retórica y poética, 1997, Porrúa, México, 520 pp. 
Kant, Immanuel, 1998, Crítica de la razón pura, (trad. Pedro Ribas), Alfaguara, Madrid, 690 pp.

Schopenhauer, Arthur, 2003 a, El mundo como voluntad y representación, vol. I., (trad. Roberto R. Aramayo), FCE, Madrid, 639 pp.

_, 2003 b, Complementos a El mundo como voluntad y representación, (trad. Pilar López de Santamaría Delgado), Trotta, Madrid, 745 pp. 